University of Nebraska - Lincoln

DigitalCommons@University of Nebraska - Lincoln

1993

\title{
An Improved Goniometer System for Calibrating Field Reference- Reflectance Panels
}

\author{
Elizabeth A. Walter-Shea \\ University of Nebraska - Lincoln, ewalter-shea1@unl.edu \\ Cynthia J. Hays \\ University of Nebraska - Lincoln, chays1@unl.edu \\ Mark A. Mesarch \\ University of Nebraska - Lincoln, mmesarch1@unl.edu
}

Follow this and additional works at: https://digitalcommons.unl.edu/natrespapers

Part of the Natural Resources and Conservation Commons, Natural Resources Management and Policy Commons, and the Other Environmental Sciences Commons

Walter-Shea, Elizabeth A.; Hays, Cynthia J.; and Mesarch, Mark A., "An Improved Goniometer System for Calibrating Field Reference-Reflectance Panels" (1993). Papers in Natural Resources. 1171.

https://digitalcommons.unl.edu/natrespapers/1171

This Article is brought to you for free and open access by the Natural Resources, School of at DigitalCommons@University of Nebraska - Lincoln. It has been accepted for inclusion in Papers in Natural Resources by an authorized administrator of DigitalCommons@University of Nebraska - Lincoln. 


\section{An Improved Goniometer System for Calibrating Field Reference-Reflectance Panels*}

Elizabeth A. Walter-Shea, Cynthia J. Hays, and Mark A. Mesarch Department of Agricultural Meteorology, University of Nebraska, Lincoln

Ray D. Jackson

USDA / ARS, U.S. Water Conservation Laboratory, Phoenix

$\boldsymbol{F}_{\text {ield reference-reflectance panels need an initial }}$ calibration and periodic recalibration to ensure valid field reflectance data. The field calibration method proposed by Jackson et al. (1987) is an affordable means to accomplish this provided that a field goniometer system is available. Design and construction details for such a system are described.

\section{INTRODUCTION}

Field reference-reflectance panels must be calibrated to account for inherent non-Lambertian properties before panel data can be used as irradiance estimates for valid reflectance factor calculations. Periodic recalibrations are essential, especially after field use, because panel surfaces may deteriorate or become contaminated with dust, which can cause changes in reflectance properties. The calibration of reference-reflectance pan-

\footnotetext{
* Paper No. 9822, J. Ser., Nebraska Agric. Res. Div.

Address correspondence to Elizabeth A. Walter-Shea, Dept. of Agricultural Meteorology, Univ. of Nebraska, P.O. Box 830728, Lincoln, NE 68583-0728.

Received 17 January 1992; revised 30 May 1992.
}

els was restricted to well-equipped laboratories until Jackson et al. (1987) reported details of a field method that offered a relatively quick, simple, and inexpensive calibration procedure. The procedure has two advantages over conventional laboratory methods. First, the method utilizes the same irradiance source (the sun) and geometry as used in field reflectance measurements. Second, the required equipment (radiometer and data logger) is the same as that used for field measurements. A disadvantage is that calibrations should only be conducted under cloud-free and low diffuse sky conditions.

The calibration of a reference-reflectance panel consists of determining the functional relationship of the panel reflectance factor to the view/irradiance angle, and comparing panel radiance to a standard surface radiance for a specified view/irradiance geometry. The standard surface should be traceable to a National Institute of Standards and Technology (NIST) Standard Reference material. A powdered polytetrafluorethylene (PTFE) panel pressed according to NIST specifications (Weidner and Hsia, 1981) was the standard surface used by Jackson et al. (1987). The key component of the calibration procedure is an apparatus that allows a panel to be held in a particular zenith and 
azimuth orientation while a measurement is made, after which the panel is rapidly changed to another orientation. The apparatus, a field goniometer, consists of a platform to which a reference panel is mounted, and a mast that holds a radiometer in a view direction normal to and a fixed distance above the panel. The platform and radiometer mast are attached to an adjustable frame which allows zenithal and azimuthal movement to achieve a prescribed angle between the sun and the panel.

Although the goniometer is essential to the field calibration procedure, Jackson et al. (1987) offered few details concerning its design and development. The objective of this report is to describe in considerable detail the construction of an improved field goniometer and the auxiliary equipment necessary to perform field reference panel calibrations.

\section{PROCEDURE}

The procedure requires a radiometer, goniometer, shading plate, reflectance standard, an inclinometer, and clear sky conditions.

Radiometer. Broad band radiometers or spectroradiometers used in the field can be used. The majority of our measurements have been made with an eight-band Barnes Modular Multiband Radiometer (MMR), ${ }^{1}$ seven bands of which are in the optical region. Nominal wavelength intervals are: $0.45-0.52 \mu \mathrm{m}, 0.52-0.60 \mu \mathrm{m}, 0.63-0.69 \mu \mathrm{m}$, $0.76-0.90 \mu \mathrm{m}, 1.15-1.30 \mu \mathrm{m}, 1.55-1.75 \mu \mathrm{m}$, and 2.08-2.35 $\mu \mathrm{m}$. The calibrations reported here were made with the Barnes MMR, although calibrations have been performed with a SE590 Spectroradiometer (Spectron Engineering, Denver, Colorado 80204) and an Exotech 100A (Exotech Inc., Gaithersburg, Maryland 20878).

Goniometer. The design used for development of the goniometer described here was adapted from the description given by Jackson et al. (1987). A schematic is shown in Figure 1. The goniometer, predominantly made of structural steel tubing, was designed and constructed by Precision

${ }^{1}$ The use of company names and brand names are necessary to report factually on available data; however, the University of Nebraska and the USDA neither guarantee nor warrant the standard of the product, and the use of the name by the University of Nebraska and the USDA implies no approval of the product to the exclusion of others that may also be suitable.
Machine Inc. (Lincoln, Nebraska 68504). The apparatus is painted flat black so that radiation incident on the goniometer is absorbed and not reflected to the reference panel mounted on the system. Four wheels attached to the base facilitate moving the apparatus to an outdoor location free of buildings or other obstructions. It can be leveled with a pair of Lab-Jacks (Cenco-Lerner Model 19089) ${ }^{1}$ and held secure with four adjustable mounting stands. The reference panel platform is inclined at the frame hinge through use of a tilting crank, worm gear, and rack and oriented by releasing the brake and pivoting the platform in the appropriate azimuth direction. Once the desired panel zenith inclination and azimuthal orientation are achieved, the platform is locked into place with a latch and braking system. The radiometer is positioned on the mast at $1.2 \mathrm{~m}$ above and normal to the center of the reference panel. Using a radiometer with a $15^{\circ}$ FOV mounted approximately $1 \mathrm{~m}$ above the platform, panels as small as $0.6 \mathrm{~m} \times 0.6 \mathrm{~m}$ and as large as $1.2 \mathrm{~m} \times 1.2 \mathrm{~m}$ can be calibrated. Reference panels must be secured on the platform, for instance, by a set of four C-clamps.

The desired solar illumination angle is the relative angle between the solar zenith angle and the panel inclination. Appropriate illumination angles are achieved through use of a sighting tube and protractor attached to the goniometer (Fig. $2)$. The sighting tube is set at predetermined relative angles on the protractor which are known through careful calibration of the sighting tube, protractor, and goniometer configuration (see below). The sighting tube is constructed of a metal cylinder $0.06 \mathrm{~m}$ in diameter and $0.20 \mathrm{~m}$ in length with a small hole in the forward end and cross-hair lines etched in glass at the other end. The goniometer platform is inclined and oriented azimuthally so that the direct light beam is aligned through the sighting hole to intercept the etched crosshair lines at the end of the tube. The alignment of the sighting tube with the direct beam is determined by observing the beam spot intersection with the cross-hair lines on a metal plate mounted $0.06 \mathrm{~m}$ away from the end of the tube. The alignment indicates that the platform is inclined at the appropriate relative angle.

Shading Plate. Diffuse sky radiation effects must be removed from data by alternately making measurements of the panel shaded and unshaded 
a)

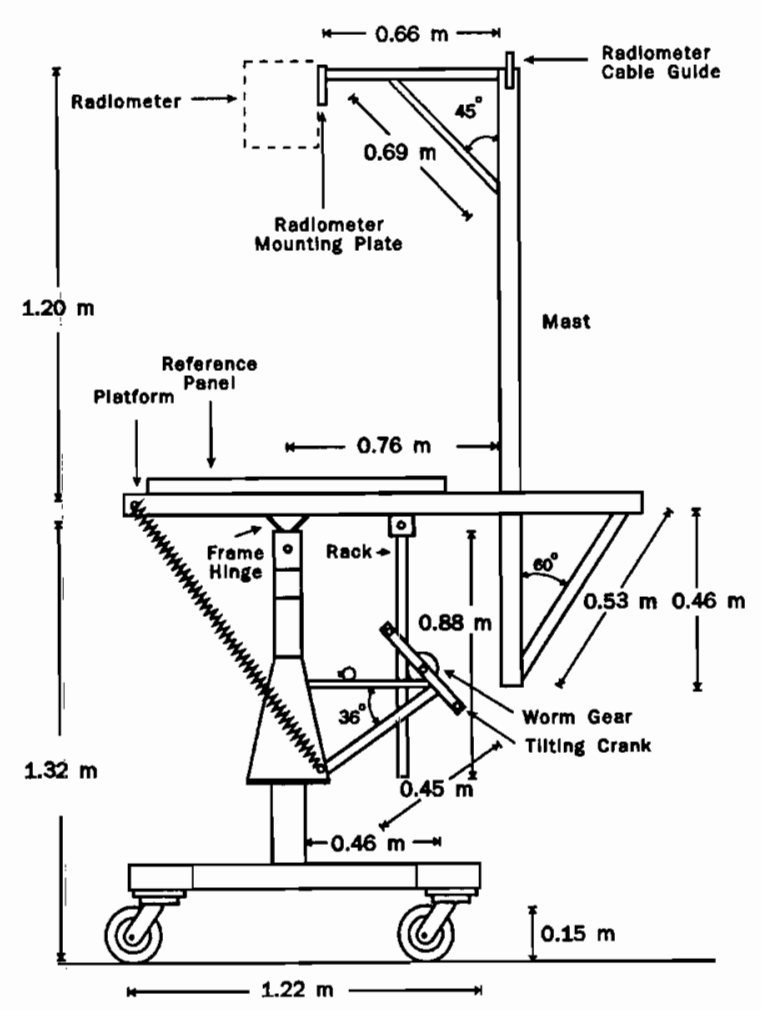

b)

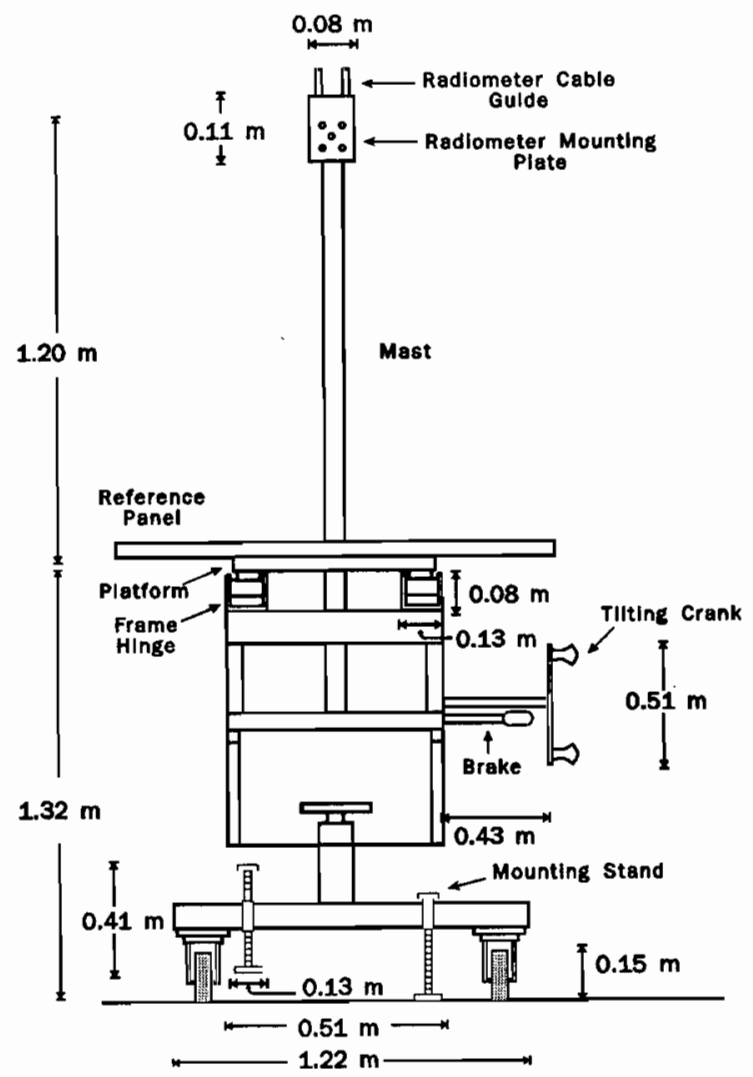

Figure 1. Schematic of goniometer: a) side and b) front views. The goniometer is predominantly constructed of steel tubing. Main features include the inclinable platform, frame hinge, tilting crank, worm gear, rack, mast, and radiometer mounting plate.

and subtracting the diffuse (average shaded) component from the total (unshaded). A shading plate was constructed from a $1.2 \mathrm{~m} \times 1.2 \mathrm{~m}$ sheet of aluminum that was bolted to a flat aluminum rod. The flat aluminum rod was welded at $45^{\circ}$ to a $0.20 \mathrm{~m}$ aluminum pipe (Fig. 3). The aluminum pipe was bolted to a $3.1 \mathrm{~m}$ length of conduit attached to a stand at the base. The shading plate, rod, and pipe should be painted flat black so that radiation is absorbed by the shading device and not reflected to the reference panel mounted on the goniometer. During a calibration measurement, the shading plate is positioned between the sun and the goniometer so that a shadow is cast on the reference panel. The sky hemisphere solid angle obscured by the shading plate varies, depending on the distance between the goniometer and the shading plate and thus the solar zenith angle lat the time of measurements. To compensate for the portion of the sky blocked by the shading plate during the diffuse measurement, the shading plate is maintained in an upright position but inclined to the side so that the shadow is cast on the platform edge during total irradiance (unshaded) measurements. The goniometer system is designed for reference panel effective illumination angles of $15-75^{\circ}$ at solar zenith angles of $40-70^{\circ}$; the sky hemisphere solid angles obscured by the shading plate vary between $0.17 \mathrm{sr}$ and $0.03 \mathrm{sr}$, equivalent to $2.7-0.5 \%$ of the sky hemisphere, respectively. The distance between the goniometer and shading plate will depend on the calibration time of day.

Reflectance Standard. A pressed PTFE standard, constructed according to NIST specifications, requires the hemispherical reflectance factors published by NIST (Wiedner and Hsia, 1981) along with the view/illumination angle relationships obtained using a goniometer to calculate directional-directional reflectance factors (Jackson et al., 1987). Labsphere ${ }^{l}$ can furnish hemispherical reflectance factors (NIST traceable) with their molded sintered PTFE-based (Spectralon) panels. The accuracy of the directional-directional 
a)

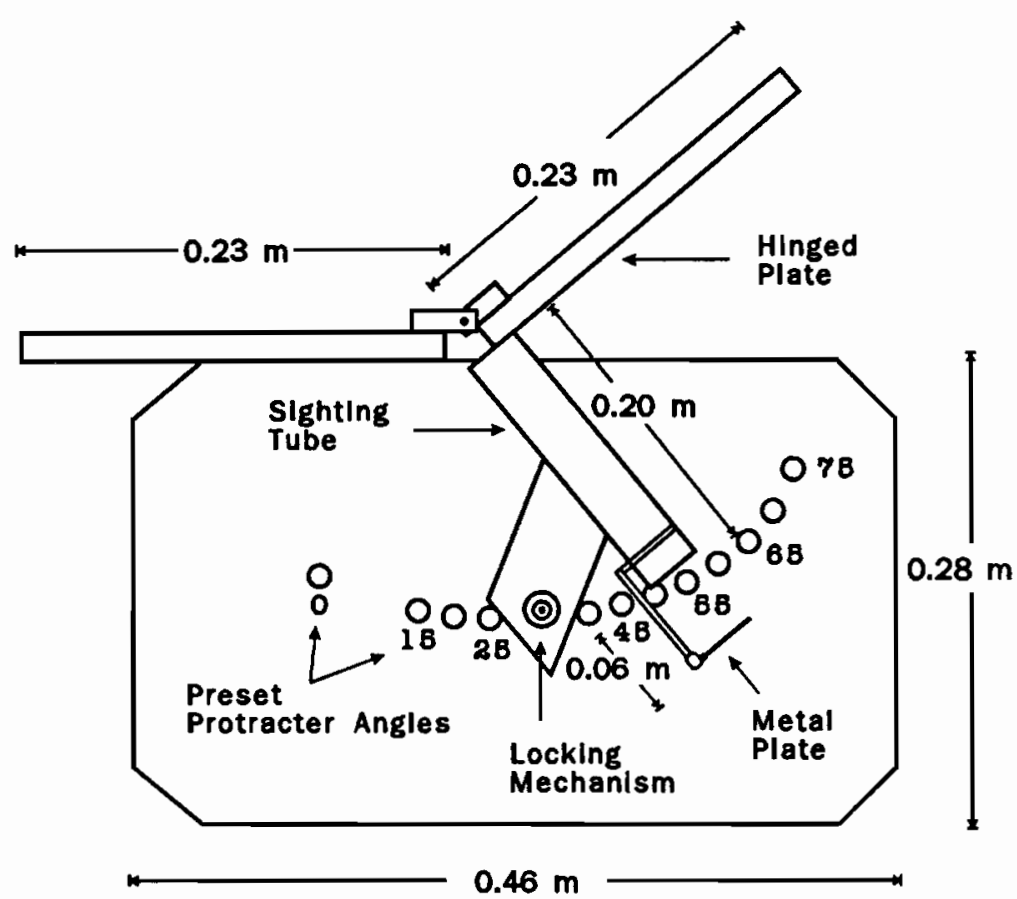

b)

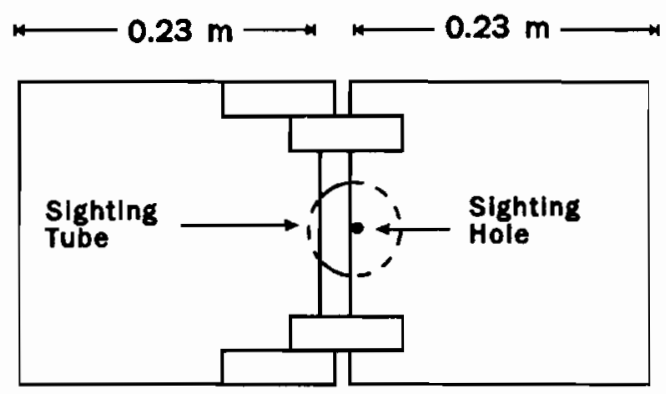

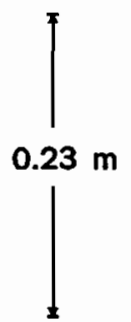

Figure 2. Schematic of sighting tube and protractor attachment for the goniometer: a) side view and b) top view. The sighting tube is used to find the appropriate illumination angle for the reference panel. The sighting tube is attached to a hinged plate and locked into place with the sighting tube angle locking mechanism. The desired effective illumination angle is achieved when the sighting tube is aligned with the incoming direct beam so that the beam intersects cross-hair lines at the back end of the tube. The beam alignment is determined by viewing the projection on the metal plate. reflectance calibration for any reflectance standard is directly dependent on the accuracy of the hemispherical reflectance measurements and the determination of the view/illumination angle relationships (Jackson et al., 1987). A Spectralon panel can be used as a standard after the view / illumination angle relationships have been determined and the directional-directional reflectance factors have been computed following the procedure outlined by Jackson et al. (1987).

Tests conducted at the U.S. Water Conservation Laboratory in Phoenix compared a Spectralon panel with a pressed PTFE panel. Results indicated that a Spectralon panel can perform as well as a pressed PTFE reflectance standard (Fig. 4). Reflectance factors calculated using the Spec- tralon panel as the standard were slightly less than those calculated using the pressed PTFE by $0.05-1.0 \%$, relatively, in all bands except Band 3, in which they were overestimated by $0.03 \%$ (Table 1).

When large $1.2 \mathrm{~m} \times 1.2 \mathrm{~m}$ field referencereflected panels are to be calibrated, the $0.6 \mathrm{~m}$ $\times 0.6 \mathrm{~m}$ standard reference panel is framed with a white painted plywood board (panel extension). The panel extension in essence "creates" a larger standard reference with an overall dimension of $1.2 \mathrm{~m} \times 1.2 \mathrm{~m}$. The panel extension is outside the nominal sensor FOV, but is made of a white reflective surface to simulate the highly reflective surface of a larger field reference panel. The extension is used to partially account for the radi- 


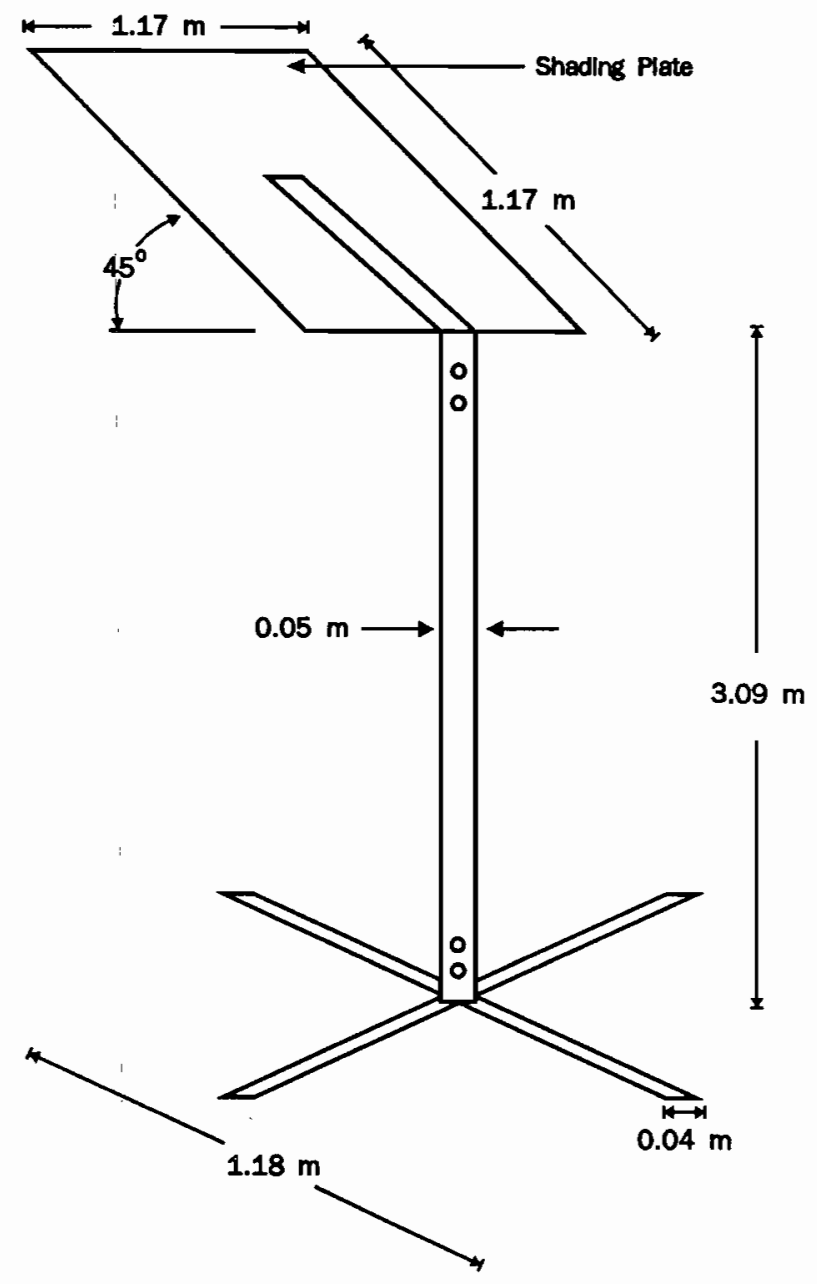

Figure 3. Schematic of the shading plate used for shading the reference panel to account for diffuse sky irradiance. The shading plate is constructed of sheet aluminum bolted to a $3.1 \mathrm{~m}$ conduit attached to a base stand.

ometer out-of-field response which may result when a $1.2 \mathrm{~m} \times 1.2 \mathrm{~m}$ field reference-reflectance panel is calibrated.

Inclinometer. Protractor angle settings on the sighting tube apparatus must be calibrated periodically since goniometer use may cause some realignment of the entire apparatus. Angle calibrations can be accomplished under field conditions (clear sky not essential but some direct beam is necessary). However, calibration at the time of or soon following panel calibrations is desirable. A digital inclinometer is a useful device to accomplish this calibration (e.g., Smart Level, Wedge Innovations, Sunnyvale, California 94086) ${ }^{1}$ This particular inclinometer is accurate to $\pm 0.1^{\circ}$. The desired angle is preset on the protractor, and the platform is aligned in zenith and azimuth

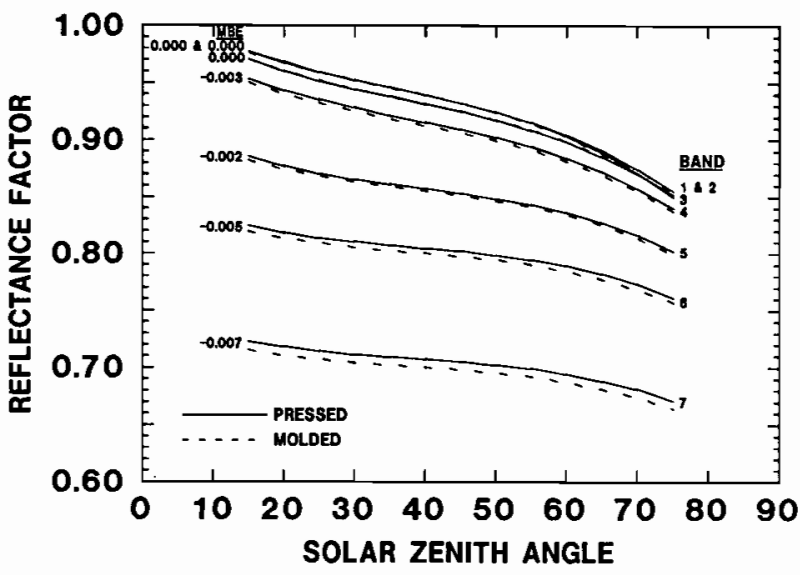

Figure 4. Reflectance factors of $\mathrm{a} \mathrm{BaSO}_{4}$ field reference panel as a function of solar zenith angle as calculated using the pressed PTFE and molded sintered PTFE-based (Spectralon) panels as standard surfaces.

directions as during a field-reference panel calibration, so that the direct beam intercepts the etched cross-hairs of the sighting tube. Time of day, latitude, and longitude are recorded for calculation of the solar declination and local hour angles from which solar zenith angle is computed (United States Naval Observatory, 1991). The digital inclinometer is placed at several locations on the platform from which an average inclination reading can be calculated. The inclination angle should be determined at all sighting tube protractor angle settings and then back again in reverse order at a total of three or more times, bracketing the reference panel calibration to compensate for any solar direction change and for repeatability determination. The effective illumination angle is calculated for each protractor setting as the difference between solar zenith and platform inclination angles. It is the true illumination angle striking the panel surface - an essential parameter for field-reference panel non-Lambertian characterization.

Clear Sky Conditions. Clear sky conditions (i.e., lack of clouds and low aerosol concentration) are essential for reliably calibrating field reference panels using the Jackson et al. method. Small variations in solar direction and optical path will occur during the procedure, which requires a minimum of approximately $30 \mathrm{~min}$ for calibrating a single reference panel. However, the procedure is designed to reduce small sky and sun variation effects. A set of measurements are made and then repeated in reverse order to average out changes 
Table 1. Statistics from Comparison of Reflectance Factors of a $\mathrm{BaSO}_{4}$ Field Reference-Reflectance Panel Calculated Using the Labsphere Spectralon and the Pressed PTFE Panels as Reference Standards at Illumination Angles of $15-75^{\circ}$ at $5^{\circ}$ Increments $^{a}$

\begin{tabular}{cccccc}
\hline Wave Band & $M B E$ & $M R E$ & $R M S E$ & $x_{\text {pressed }}$ & $x_{\text {spec }}$ \\
\hline 1 & 0.000 & -0.33 & 0.001 & 0.925 & 0.925 \\
2 & 0.000 & -0.05 & 0.001 & 0.926 & 0.925 \\
3 & 0.000 & 0.03 & 0.000 & 0.919 & 0.919 \\
4 & -0.003 & -0.32 & 0.003 & 0.904 & 0.901 \\
5 & -0.002 & -0.27 & 0.002 & 0.849 & 0.847 \\
6 & -0.005 & -0.58 & 0.005 & 0.798 & 0.793 \\
7 & -0.007 & -1.01 & 0.007 & 0.702 & 0.695 \\
$N=13$ & & & & &
\end{tabular}

${ }^{a} \mathrm{MBE}=$ Mean bias error $=N^{-1} \sum\left(E_{i}-M_{i}\right)$, where $N=$ number of observation, $E_{i}=$ estimated value at time $i$, and $M_{\mathrm{i}}=$ measured value at time $i$. MRE = mean relative error = $N^{-1}\left[\Sigma\left(E_{i}-M_{i}\right) / M_{i}\right][100]$. RMSE $=$ root mean square error $=\left[N^{-1} \sum\left(M_{i}-E_{i}\right)^{2}\right]^{1 / 2} \cdot x=$ mean reflectance factor $=N^{-1} \Sigma V_{i}$, where $V_{i}=$ estimated or measured values.

in sky condition. The panel-reflectance-factor/ solar-zenith-angle functional relationship is determined by inclining the panel so that it is effectively illuminated at $15-75^{\circ}$ angles and then in reverse order. The value representing radiance from the panel for each effective illumination angle $\left(15-75^{\circ}\right)$ is the average of two instrumentoutput values (proportional to radiance from the panel, e.g., voltage, counts) measured at the appropriate goniometer inclinations.

\section{COSTS}

Estimated costs for the standard reference, inclinometer, and construction of the goniometer and shading plate are listed in Table 2.

\section{MEASUREMENT REPEATABILITY}

Solar Zenith and Goniometer Platform Inclinations. Error analysis indicates that errors associated with

Table 2. Estimated Costs for Field Calibration Goniometer System $^{a}$

\begin{tabular}{lr}
\hline \multicolumn{1}{c}{ Item } & \multicolumn{1}{c}{ Cost } \\
\hline Labsphere $0.6 \mathrm{~m} \times 0.6 \mathrm{~m}$ Spectralon panel & $\$ 2800$ \\
NIST traceable calibration from $250 \mathrm{~nm}$ to $2500 \mathrm{~nm}$ & 300 \\
Wedge Innovations digital level & 100 \\
Goniometer construction & 3800 \\
Shading plate construction & 100 \\
Total & $\$ 7100$ \\
\hline
\end{tabular}

${ }^{a}$ Prices shown are estimates and may change due to construction material costs. defining latitude and longitude of the calibration site resulted in calculation errors of $\pm 0.044^{\circ}$ and $\pm 0.0017^{\circ}$ for local hour angle and solar declination angles, respectively. The effect of these errors on solar zenith angle computations were analyzed by calculating solar zenith angles without error terms and then with different combinations of error terms. Including the error resulting from refraction of the direct beam, solar zenith angle calculation errors ranged from $-0.065^{\circ}$ to $+0.063^{\circ}$, within the digital inclinometer accuracy.

Experimental errors of the sighting tube/goniometer platform inclination were quantified through repeated measures of effective illumination angle measurements (seven sets of three measurements). Means of each measurement set differed as much as -0.19 to $+0.21^{\circ}$ and is attributed to errors in solar zenith angle calculation, digital level accuracy, variation along the goniometer platform, and sighting the direct beam through the sighting tube apparatus.

Reference Panel. The ability of the technique to obtain the same calibration coefficient for the same standard reference panel was determined by repeating the calibration procedure (calibration of the panel and effective illumination angles) four times under four different solar zenith angle conditions. Thus, the relationship between the directional-directional reflectance factor and effective illumination angle was determined four times. Reflectance values were calculated for each of the four runs from $15^{\circ}$ to $75^{\circ}$ zenith angle. Changes in reflectance factor values can be attributed to experimental errors (goniometer inclination cali- 
Table 3. Statistics from Comparison of Field Reference Panel Reflectance Factors Calculated from Pre- and Postseason Calibrations over Solar Illumination Angles of $15-75^{\circ}$ at $5^{\circ}$ Increments $^{a}$

\begin{tabular}{|c|c|c|c|c|c|}
\hline Wave Band & $M B E$ & $M R E$ & RMSE & $x_{\text {pre }}$ & $x_{\text {post }}$ \\
\hline 1 & -0.043 & -4.40 & 0.044 & 0.991 & 0.948 \\
\hline 2 & -0.034 & -3.45 & 0.034 & 0.993 & 0.959 \\
\hline 3 & -0.026 & -2.59 & 0.026 & 0.993 & 0.968 \\
\hline 4 & -0.017 & -1.72 & 0.017 & 0.993 & 0.976 \\
\hline 5 & -0.008 & -0.85 & 0.009 & 0.991 & 0.982 \\
\hline 6 & -0.004 & -0.46 & 0.005 & 0.988 & 0.984 \\
\hline 7 & -0.001 & -0.08 & 0.004 & 0.960 & 0.959 \\
\hline$N=13$ & & & & & \\
\hline
\end{tabular}

${ }^{a}$ For definition of statistics see Table 1.

bration and sighting of the direct beam through the sighting tube) since the hemispherical values and non-Lambertian properties of the panels are the same. The standard deviations of the reflectance factors ranged between 0.002 and 0.005 across all wave bands for illumination angles of $15-65^{\circ}$, between 0.006 and 0.007 for a $70^{\circ}$ illumination angle, and between 0.012 and 0.013 for a $75^{\circ}$ illumination angle. Standard deviations for effective illumination angles of $15-65^{\circ}$ are comparable to standard deviations arrived by Jackson et al. (1992) from repeated measures of a pressed PTFE standard reference. However, standard deviations are higher at $70^{\circ}$ and $75^{\circ}$ effective illumination than those of Jackson et al. Variations in results are attributable to experimental errors, including the use of a new set of goniometer inclination values for each run (following the suggested procedure). However, the variation among the four runs results in an absolute difference of less than 0.005 between the means of the reflectance factors. In addition, no correction was made for the shadow cast on the panels by the MMR at the lowest illumination angles. The shadow is outside the FOV of the MMR but results indicate that wave bands 1 and 7 are influenced by shadow (due to MMR size and the circular sensor configuration on the MMR faceplate). Reflectance factor values for wave bands 1 and 7 are lower at the $15^{\circ}$ illumination angle than at the $20^{\circ}$ illumination angle whereas reflectance factor values at the $15^{\circ}$ illumination angle for wave bands $2-6$ are not lower than those at the $20^{\circ}$ illumination angle.

\section{EXAMPLE RESULTS OF FIELD PANEL CALIBRATION}

A $1.2 \mathrm{~m} \times 1.2 \mathrm{~m}$ Spectralon panel was calibrated using a $0.6 \mathrm{~m} \times 0.6 \mathrm{~m}$ NIST traceable calibrated Spectralon standard reference mounted in a whitepainted panel extension using the described goniometer system and the procedure outlined by Jackson et al. (1987). Spectralon panels are ideal for field use because they have washable surfaces (Schutt et al., 1981). The panel was calibrated before and after a 16-week period of field use as

Table 4. Statistics ${ }^{a}$ from Comparison of Alfalfa Canopy Reflectance Factors Using Pre- and Postseason Panel Calibration Values to Correct Panel Reflectance Properties for Computation of Reflectance Factors When Postseason Values Should Have Been Used

\begin{tabular}{cccccc}
\hline Wave Band & MBE & MRE & $R M S E$ & $x_{\text {pre }}$ & $x_{\text {post }}$ \\
\hline 1 & -0.002 & -4.58 & 0.002 & 0.039 & 0.037 \\
2 & -0.002 & -3.46 & 0.002 & 0.055 & 0.053 \\
3 & -0.001 & -2.62 & 0.001 & 0.037 & 0.036 \\
4 & -0.008 & -1.72 & 0.008 & 0.468 & 0.460 \\
5 & -0.003 & -0.78 & 0.003 & 0.431 & 0.427 \\
6 & -0.001 & -0.41 & 0.001 & 0.244 & 0.243 \\
7 & -0.000 & -0.13 & 0.000 & 0.094 & 0.094 \\
$N=660$ & & & & & \\
\hline
\end{tabular}

${ }^{a}$ For definition of statistics see Table 1. 
a means of testing the goniometer system and determining degradation or dust effect on panel reflectance properties and canopy reflectance factor calculations.

Exposure of the field reference-reflectance panel to field conditions particularly affected reflectance properties in the visible spectrum (Table 3 ). Although reflectance of the pre- and postseason panels were still quite high, the postseason panel reflectance factors were lower by as much as 0.043 in Band 1 and as little as 0.001 in Band 7 (within the 0.005 calibration error) over solar illumination angles of $15-75^{\circ}$ at $5^{\circ}$ increments (mean relative error range of $4.40-0.08 \%$, respectively).

Using a preseason panel calibration rather than an appropriate postseason panel calibration to correct panel reflectance properties can result in calculated canopy reflectance factor errors. As an example, canopy reflectance factors, calculated from data collected under a variety of solar and view zenith angle conditions for an alfalfa canopy, were computed using the incorrect preseason panel calibration when postseason values should have been used (Table 4). Canopy reflectance factors were overestimated using preseason reference panel calibration values. Although small in absolute terms, the relative errors indicate that if field reference-reflectance panels are not calibrated frequently, canopy reflectance factors in the visible spectrum can be overestimated relatively by $2-4 \%$ and by $1.5 \%$ in the NIR. Less frequent calibrations (1-2 years) of field reference-reflectance panels used frequently in the field may result in serious errors.

\section{CONCLUDING REMARKS}

A fairly rapid, simple and accurate means of calibrating field reference-reflectance panels is achiev- able with the goniometer system described here. An initial investment is required in the purchase (or construction) of an NIST traceable calibrated standard reference, an inclinometer, and the construction of a goniometer and shading plate. Frequent calibrations are suggested (a minimum of three, i.e., pre-, mid-, and postseason) for accurate and reliable calculations of reflectance factors because dust, use, and surface deterioration can cause panel reflectance changes. Without readily available calibration facilities, there is a tendency to postpone panel calibrations for several years to the detriment of accurate field reflectance measurements.

Funds for development of the improved goniometer system were provided by the Agricultural Research Division, University of Nebraska. The authors wish to thank Dan Gee and John Buse of Precision Machine for their assistance in the design and construction of the goniometer, sighting tube, and protractor and Susan Moran and Buzz Martin for their suggestions toward improving the article.

\section{REFERENCES}

Jackson, R. D., Clarke, T. R., and Moran, M. S. (1992), Bidirectional calibration results for 11 molded halon and $16 \mathrm{BaSO}_{4}$ reference reflectance panels, Remote Sens. Environ., 40:231-239.

Jackson, R. D., Moran, M. S., Slater, P. N., and Biggar, S. F. (1987), Field calibration of reference reflectance panels, Remote Sens. Environ. 22:145-158.

Schutt, J. B., Holben, B. N., Shai, C. M., and Henninger, J. H. (1981), Reflectivity of TFE - a washable surfacecompared with that of $\mathrm{BaSO}_{4}$, Appl. Opt. 20(12):20332035.

United States Naval Observatory (1991), Almanac for Computers, Government Printing Office, Washington, DC.

Weidner, V. R., and Hsia, J. J. (1981), Reflection properties of pressed polytetrafluoroethylene powder, J. Opt. Soc. Am. 71:856-861. 